\title{
A comparison of the changes in cardiac output and systemic vascular resistance during exercise following high-fat meals containing DHA or EPA
}

\author{
Victoria G. Rontoyanni*, Wendy L. Hall, Sonia Pombo-Rodrigues, Amber Appleton, Roxanna Chung \\ and Thomas A. B. Sanders \\ Diabetes and Nutritional Sciences Division, School of Medicine, King's College London, Franklin-Wilkins Building, \\ 150 Stamford Street, London SE1 9NH, UK
}

(Submitted 17 February 2011 - Final revision received 20 September 2011 - Accepted 20 September 2011 - First published online 21 February 2012)

\begin{abstract}
Long-chain $n$-3 PUFA can lower blood pressure (BP) but their acute effects on cardiac output, BP and systemic vascular resistance (SVR) in response to dynamic exercise are uncertain. We compared the effects of high-fat meals rich in EPA (20:5n-3), DHA (22:6n-3) or oleic acid (control) on cardiac output, BP and SVR in response to exercise stress testing. High-fat meals ( $50 \mathrm{~g}$ fat) containing high-oleic sunflower oil enriched with $4.7 \mathrm{~g}$ of either EPA or DHA $v$. control (high-oleic sunflower oil only) were fed to twenty-two healthy males using a randomised cross-over design. Resting measurements of cardiac output, heart rate and BP were made before and hourly over $5 \mathrm{~h}$ following the meal. A standardised 12 min exercise test was then conducted with further measurements made during and post-exercise. Blood samples were collected at fasting, $5 \mathrm{~h}$ postprandially and immediately post-exercise for the analysis of lipid, glucose and 8-isoprostane- $\mathrm{F}_{2 \alpha}$ (8-iso$\mathrm{PGF}_{2 \alpha}$ ). Plasma concentrations of EPA and DHA increased by $0.22 \mathrm{mmol} / 15 \mathrm{~h}$ following the EPA and DHA meals, respectively, compared with the control $(P<0 \cdot 001)$. Resting cardiac output and 8-iso- PGF $_{2 \alpha}$ increased similarly following all meals and there were no significant differences in cardiac output during exercise between the meals. SVR was lower at $5 \mathrm{~h}$ and during exercise following the DHA but not EPA meal, compared with the control meal, by $4.9 \%$ (95\% CI 1.3, 8.4; P<0.01). Meals containing DHA appear to differ from EPA with regard to their effects on cardiovascular haemodynamics during exercise.
\end{abstract}

Key words: DHA: EPA: $\boldsymbol{n}$-3 Fatty acids: Blood pressure: Exercise

The chronic blood pressure (BP)-lowering effects of $n$ - 3 longchain PUFA (LCP), primarily of EPA $(20: 5 n-3)$ plus DHA (22:6n-3) supplementation, are well established ${ }^{(1)}$, with DHA possibly being the main contributor to this effect ${ }^{(2,3)}$. Evidence to date suggests that the effect is a result of a decrease in systemic vascular resistance (SVR) rather than in cardiac output ${ }^{(4,5)}$. Possible mechanisms for this effect include increased NO bioavailability, changes in endothelium-derived hyperpolarising factor (EDHF) and altered eicosanoid profiles ${ }^{(6-10)}$.

Relatively few studies have investigated the acute effects on vascular function of meals rich in EPA and DHA. There is some evidence for a positive effect of EPA and DHA on endothelial and vascular function when added to high-fat meals ${ }^{(11-14)}$. Improvements in arterial stiffness have been reported following meals enriched with $4.7 \mathrm{~g} \mathrm{EPA}^{(15)}$ or a mixture of $4.7 \mathrm{~g} \mathrm{EPA}$ and $\mathrm{DHA}^{(16)}$. However, there have been no systematic comparisons between EPA- and DHA-rich meals.

Sympathetic nerve activity increases in response to exercise to facilitate increases in BP. However, sympathetic vasoconstriction is attenuated in the exercising skeletal muscle vasculature, with NO, PG and a cytochrome P450-derived product (possibly involved in the EDHF-mediated response) being partially responsible for exercise hyperaemia ${ }^{(17,18)}$ and the exercise-induced reduction in $\mathrm{SVR}^{(19)}$. Impaired endothelial function and exercise-induced vasodilation have been associated with an exaggerated BP response to exercise ${ }^{(20,21)}$, which may contribute to the development of future hypertension and its complications ${ }^{(22,23)}$. The acute effects of EPA and/or DHA on cardiovascular haemodynamics in response to dynamic exercise are currently uncertain. We hypothesised that meals containing $n$-3 LCP, EPA or DHA would improve exercise-induced vasodilation, as indicated by a decrease in exercise SVR, and attenuate the increase in exercise BP.

\section{Subjects and methods}

\section{Participants and screening procedure}

Healthy men, aged 18-45 years, were recruited from staff and students of King's College London (London, UK). Exclusion

Abbreviations: 8-iso-PGF ${ }_{2 \alpha}, 8$-isoprostane- $\mathrm{F}_{2 \alpha}$; BP, blood pressure; EDHF, endothelium-derived hyperpolarising factor; HR, heart rate; LCP, long-chain PUFA; MAP, mean arterial pressure; SVR, systemic vascular resistance. 
Fish oils and cardiovascular haemodynamics

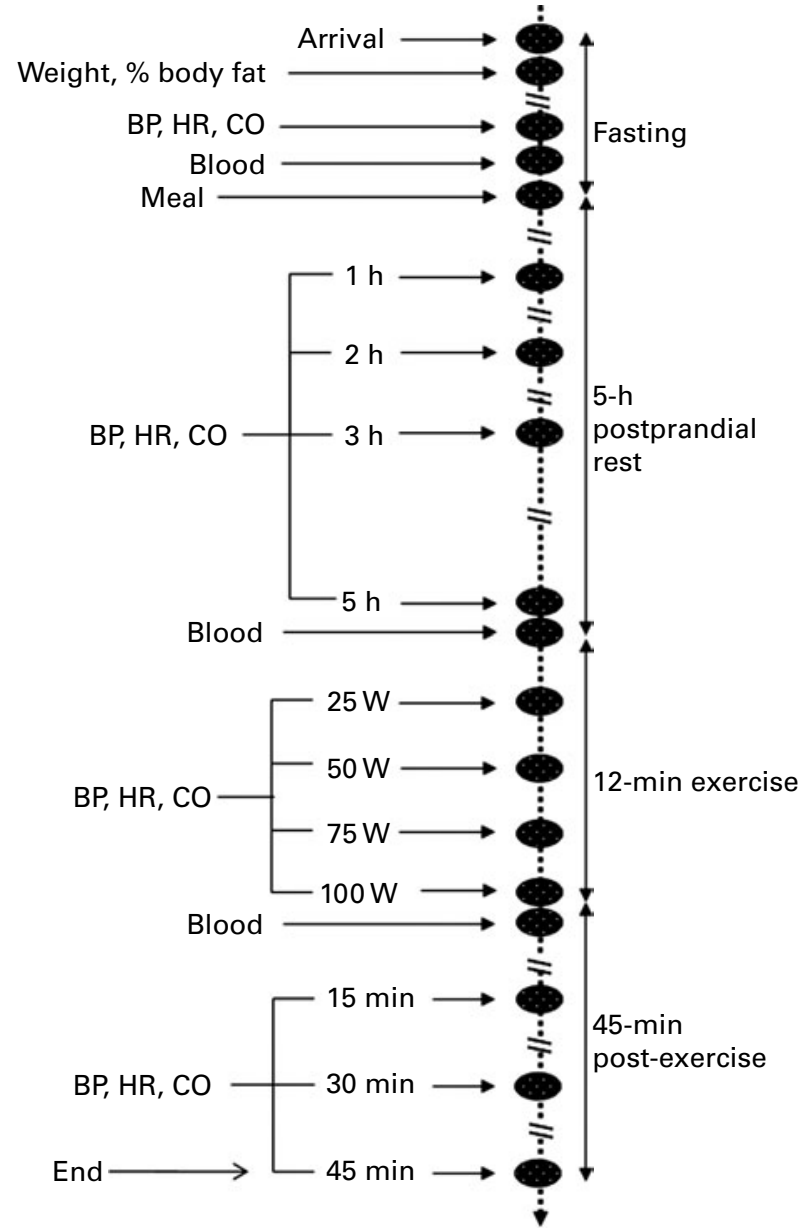

Fig. 1. Outline of the study days. BP, blood pressure; HR, heart rate; $\mathrm{CO}$, cardiac output.

criteria were as follows: current smoking habit; consumption of more than one portion of oily fish per week and/or regular fish oil supplementation within the past 3 months; $\mathrm{BMI} \leq 18.0$ or $\geq 30 \mathrm{~kg} / \mathrm{m}^{2}$; $\mathrm{BP} \geq 140 / 90 \mathrm{mmHg}$; plasma total cholesterol $>7.8 \mathrm{mmol} / \mathrm{l}$; plasma TAG $>3.0 \mathrm{mmol} / \mathrm{l}$; diabetes mellitus (fasting plasma glucose $>7 \cdot 0 \mathrm{mmol} / \mathrm{l}$ ); abnormal haematology or liver function tests; self-reported history of myocardial infarction, angina, venous thrombosis, stroke, cancer, presence of gastrointestinal disorder; self-reported weekly alcohol intake of $>28$ standard units of alcohol ( 1 unit $=10 \mathrm{ml}$ ethanol); systematic use of any medication. The study was conducted according to the guidelines laid down in the Declaration of Helsinki and all procedures involving human subjects were approved by the National Research Ethics Service (07/H0809/54). Participants were given a detailed outline of the study requirements and all provided written informed consent. The trial was registered at clinicaltrials.gov as ISRCTN62232400.

Body weight, BP, fasting plasma lipoprotein lipid concentrations, glucose, haematology and liver function were confirmed to be within the prescribed limits before entry into the study as described previously ${ }^{(24)}$. To identify and exclude those with a high consumption of oily fish, a short FFQ was used, which consisted of fifteen questions related to fish consumption. Waist circumference was measured to the nearest $0.1 \mathrm{~cm}$ using a plastic tape measure and percentage of body fat was estimated using bioelectrical impedance (model: BC-418 MA; Tanita UK Limited, Middlesex, UK). In order to ensure that participants were suitable to undertake the exercise test, $\mathrm{VO}_{2 \max }$, an index of cardiorespiratory fitness, was estimated using the Astrand-Rhyming cycle ergometer test, nomogram and age correction factor ${ }^{(25,26)}$, as detailed elsewhere ${ }^{(24)}$.

\section{Experimental design}

A single-blind, randomised, cross-over study design was undertaken to test the effects of high-fat meals $(50 \mathrm{~g}$ total fat) containing high-oleic sunflower oil enriched with $4.7 \mathrm{~g}$ of either EPA or DHA, compared with control (high-oleic sunflower oil only). Subjects were allocated to one of six treatment sequences in random order ( $\mathrm{ABC}, \mathrm{ACB}, \mathrm{BAC}, \mathrm{BCA}$, CAB, CBA - orthogonal Latin square design). Each study day lasted for approximately $8 \mathrm{~h}$ and study days were separated by at least 1 week during which subjects were instructed to avoid fish consumption, especially oily fish. On the day before the test meal, subjects were asked to avoid alcohol, fish intake, foods high in fat, caffeine from midday and to refrain from vigorous exercise, and they were provided with a standardised low-fat dinner $(\leq 10 \mathrm{~g}$ fat) for their evening meal. They were further asked to fast from 22.00 hours the previous night, avoiding everything apart from water and to refrain from exercise in the morning of the study.

Participants attended the metabolic research unit between 08.00 and 11.00 hours, weight was measured and percentage of body fat was estimated. Following a 20 min quiet, seated rest period, measurements of $\mathrm{BP}$, heart rate $(\mathrm{HR})$ and cardiac output were made in duplicate and a fasting venous blood sample was obtained for the measurement of plasma lipids, glucose and 8-isoprostane- $\mathrm{F}_{2 \alpha}$ (8-iso- $\left.\mathrm{PGF}_{2 \alpha}\right)$. Participants then consumed the high-oleic acid test meal (either EPA, DHA or control) within 10 min. Further seated measurements of BP, HR and cardiac output were repeated $1,2,3$ and $5 \mathrm{~h}$ postprandially. Between measurements, participants rested quietly in living room areas of the research unit, where they could read or use a laptop computer. A further venous blood sample was obtained at $5 \mathrm{~h}$ following the meal, followed by a 12 min multi-stage exercise stress test of moderate intensity on a programmable electrically braked cycle

Table 1. Nutrient composition of the test meals

\begin{tabular}{lccc}
\hline Nutrients & EPA & DHA & Control \\
\hline Energy (kJ) & 3530 & 3530 & 3530 \\
Carbohydrate $(\mathrm{g})$ & 86 & 86 & 86 \\
Protein $(\mathrm{g})$ & 15 & 15 & 15 \\
Fat $(\mathrm{g})$ & 50 & 50 & 50 \\
SFA $(\mathrm{g})$ & 3 & 3 & 3 \\
MUFA (g) & 35 & 35 & 41 \\
PUFA (g) & 9 & 9 & 4 \\
$n-3$ PUFA (g) & 5.7 & 6.0 & 0.1 \\
EPA $(20: 5 n-3)(\mathrm{g})$ & 4.7 & 1.1 & 0 \\
DHA $(22: 6 n-3)(\mathrm{g})$ & 0.7 & 4.7 & 0 \\
\hline
\end{tabular}


Table 2. Details of the male participants

\begin{tabular}{|c|c|c|}
\hline & \multicolumn{2}{|c|}{ Males (n 22) } \\
\hline & Mean & SD \\
\hline Age (years) & $23 \cdot 0$ & 3.6 \\
\hline BMI $\left(\mathrm{kg} / \mathrm{m}^{2}\right)$ & $23 \cdot 3$ & $2 \cdot 7$ \\
\hline Body fat $(\%)$ & $15 \cdot 4$ & $5 \cdot 1$ \\
\hline Waist circumference (cm) & $80 \cdot 2$ & $5 \cdot 0$ \\
\hline $\mathrm{VO}_{2 \max }(\mathrm{ml} / \mathrm{kg}$ per min $)$ & $46 \cdot 2$ & $9 \cdot 0$ \\
\hline Serum total cholesterol $(\mathrm{mmol} / \mathrm{l})$ & 4.02 & 0.82 \\
\hline Serum LDL-cholesterol ( $\mathrm{mmol} / \mathrm{l})$ & $2 \cdot 39$ & 0.64 \\
\hline Serum HDL-cholesterol $(\mathrm{mmol} / \mathrm{l})$ & 1.37 & 0.34 \\
\hline Serum TAG $(\mathrm{mmol} / \mathrm{l})$ & 0.84 & 0.32 \\
\hline Plasma glucose (mmol/l) & $5 \cdot 16$ & 0.32 \\
\hline Systolic BP (mmHg) & 117.6 & 8.0 \\
\hline Diastolic BP (mmHg) & 71.4 & $6 \cdot 7$ \\
\hline
\end{tabular}

$\mathrm{BP}$, blood pressure.

ergometer, which has previously been used in similar study protocols $^{(23,24,27)}$. Workload increased by $25 \mathrm{~W}$ in $3 \mathrm{~min}$ intervals, starting at $25 \mathrm{~W}$ and pedalling frequency was kept constant at $60 \mathrm{rpm}$. During exercise, further measurements of BP, HR and cardiac output were determined at 3, 6, 9 and $12 \mathrm{~min}$. Immediately post-exercise, a further venous blood sample was collected. Then, the subjects were allowed to recover seated and further measurements of BP, HR and cardiac output were determined at 15, 30 and $45 \mathrm{~min}$ postexercise. An outline of the study protocol is shown in Fig. 1.

\section{Formulation of the test meals}

The test meals were matched for volume, energy, total fat, protein and carbohydrate content, consisted of a muffin and a milkshake and were similar, except for the type of fat, to those described previously ${ }^{(24)}$. The oil in the control meal was provided by high-oleic sunflower oil (Archer Daniel Mills Limited, Erith, Kent, UK) and the oil in the EPA and DHA-rich meals was formulated by blending $42 \mathrm{~g}$ high-oleic sunflower oil with $8 \mathrm{~g}$ of the respective concentrate (Incromega EPA 500TG SR and Incromega DHA 500TG SR; Croda Chemicals Europe Limited, Goole, UK). Fatty acid analyses of the test fats were performed and the nutrient content of the test meals were estimated as described previously ${ }^{(24)}$. The nutrient composition of the test meals is shown in Table 1.

\section{Haemodynamic measurements}

A single trained investigator (V. G. R.) conducted all measurements with the subject relaxing in an upright, seated position in a quiet and temperature-controlled $\left(23^{\circ} \mathrm{C}\right)$ room. Cardiac output was measured non-invasively using an inert gas rebreathing device (InnoCor ${ }^{\mathrm{TM}}$; Innovision $\mathrm{A} / \mathrm{S}$, Odense, Denmark). A finger arterial BP monitor, the Finometer ${ }^{\mathrm{TM}}$ Model-1 (Finapres Medical Systems BV, Amsterdam ZO, The Netherlands), was used to measure systolic and diastolic BP, mean arterial pressure (MAP) and HR on a beat-to-beat basis.

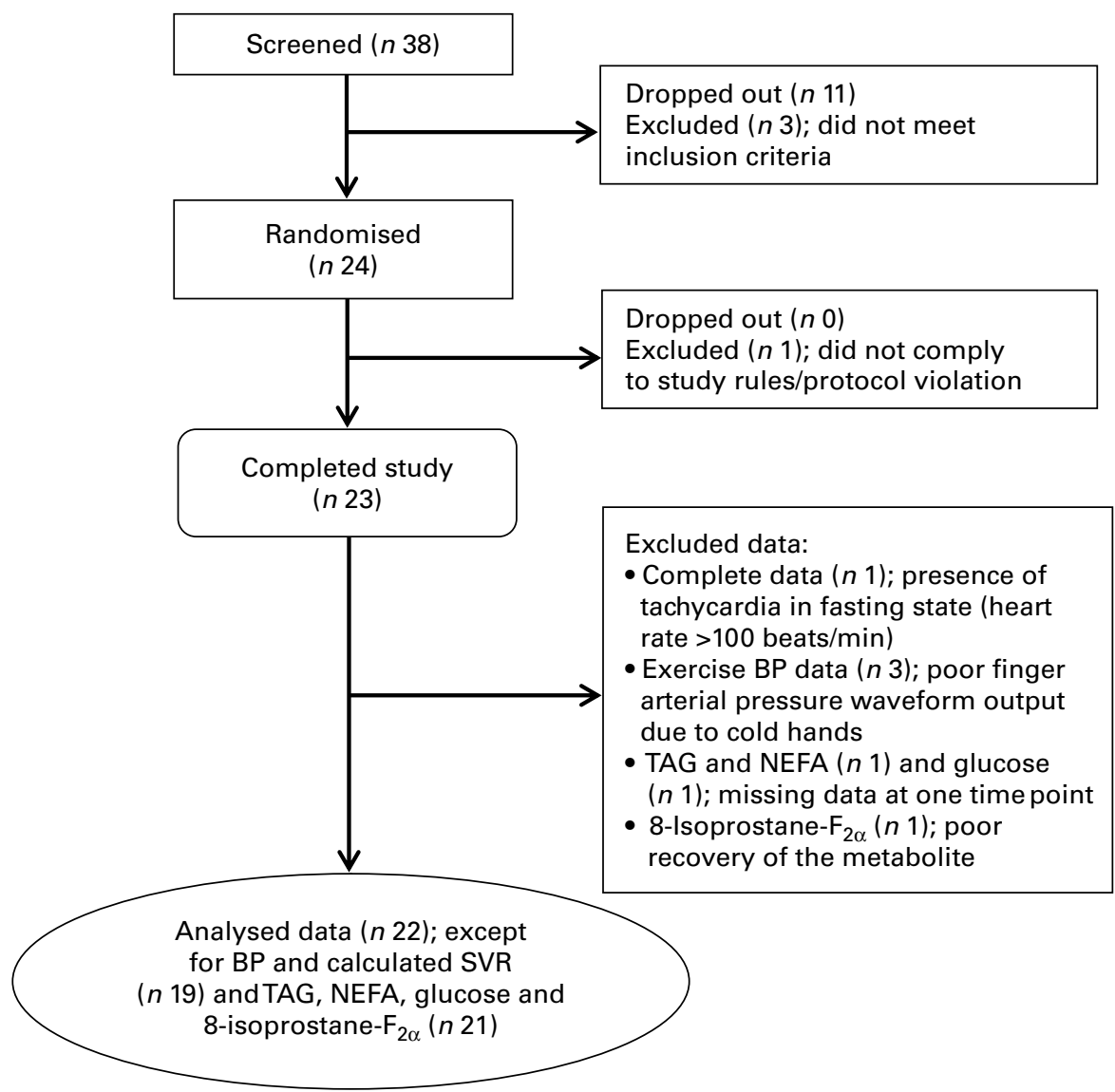

Fig. 2. CONSORT (Consolidated Standards of Reporting Trials) flow chart of the study participants. BP, blood pressure; SVR, systemic vascular resistance. 
The Finometer offers continuous monitoring of the finger arterial pressure waveform and has been shown to provide reliable data during exercise ${ }^{(28)}$. Application of corrective measures, such as waveform filtering and level correction, a height correction system and arm-cuff return-to-flow calibration provides accurate BP measurement ${ }^{(29)}$. The finger cuff was applied on the index finger of the left hand and the arm cuff wrapped around the left arm. Values for BP, MAP and HR represent means for $30 \mathrm{~s}$ epochs for resting and post-exercise measures and means for 5-15s epochs during exercise, all recorded immediately before each cardiac output rebreathing manoeuvre to avoid overestimation due to forced rebreathing. Stroke volume was calculated from cardiac output divided by HR values. SVR was estimated from MAP divided by cardiac output.

\section{Blood sample collection, handling and analysis}

Venous blood samples were collected into evacuated tubes with minimal compression necessary to display the vein. Blood for the analysis of 8 -iso-PGF $2 \alpha$ was collected into prechilled $4.5 \mathrm{ml}$ tubes (catalogue no. 369714; Becton Dickinson, Plymouth, Devon, UK) containing $0.5 \mathrm{ml}$ trisodium citrate $(0 \cdot 105 \mathrm{~mol} / \mathrm{l})$ and processed as described previously ${ }^{(24)}$,

(Mean values and $95 \%$ confidence intervals) and the samples were stored at $-80^{\circ} \mathrm{C}$ until analysis by $\mathrm{GC} /$ negative chemical ionisation MS, as detailed elsewhere ${ }^{(15)}$ Blood for plasma total fatty acids, TAG and NEFA was collected into $6 \mathrm{ml}$ EDTA-containing tubes (catalogue no. 367863; Becton Dickinson) and for plasma glucose into a $4 \mathrm{ml}$ fluoride/oxalate tube (catalogue no. 367922; Becton Dickinson). Blood was then centrifuged at $2400 \mathrm{~g}$ for $15 \mathrm{~min}$ at $2-4^{\circ} \mathrm{C}$ and plasma samples were stored at $-40^{\circ} \mathrm{C}$ until analysis. Plasma TAG, NEFA and glucose were measured on an automated chemistry analyser (ILAB-650; Instrumentation Laboratory, Warrington, Cheshire, UK) using colorimetric assays (TAG and glucose: catalogue no. 0018255640 and catalogue no. 00018250740, Instrumentation Laboratory; NEFA C: catalogue no. 999-75406, Wako Chemicals GmbH, Neuss, Germany). Plasma total fatty acids were analysed by GLC as described previously ${ }^{(30)}$.

\section{Statistical analysis}

Sample size calculations were based on a within-subject standard deviation of 1.09 litres/min and a correlation coefficient of 0.88 for cardiac output and a within-subject standard deviation of differences of $4.9 \mathrm{mmHg}$ for diastolic BP; these gave $80 \%$ power at $P<0.05$ for a sample size of twenty-two subjects

Table 3. Changes in plasma EPA, DHA and oleic acid concentrations ( $n$ 22), plasma TAG, NEFA, glucose and 8-isoprostane- $\mathrm{F}_{2 \alpha}\left(8-\right.$ iso-PGF $_{2 \alpha} ; n$ 21) after the EPA, DHA and control meals from fasting $(0 \mathrm{~h})$ at $5 \mathrm{~h}$ and immediately post-exercise

\begin{tabular}{|c|c|c|c|c|c|c|}
\hline & \multicolumn{2}{|c|}{ Fasting $(0 \mathrm{~h})$} & \multicolumn{2}{|c|}{$\Delta(5-0 h)$} & \multicolumn{2}{|c|}{$\Delta$ (Post-exercise $-0 \mathrm{~h})$} \\
\hline & Mean & $95 \% \mathrm{Cl}$ & Mean & $95 \% \mathrm{Cl}$ & Mean & $95 \% \mathrm{Cl}$ \\
\hline \multicolumn{7}{|c|}{ Plasma EPA $(\mu \mathrm{mol} / \mathrm{l})^{*} \dagger$} \\
\hline EPA & $69 \cdot 8$ & $52 \cdot 9,87 \cdot 0$ & $224 \cdot 2^{a}$ & $135 \cdot 6,312 \cdot 8$ & $264 \cdot 8^{a}$ & $178 \cdot 2,351 \cdot 5$ \\
\hline $\mathrm{DHA}$ & $71 \cdot 1$ & $55 \cdot 5,87 \cdot 0$ & $59 \cdot 5^{\mathrm{b}}$ & $27 \cdot 8,91 \cdot 6$ & $71 \cdot 7^{\mathrm{b}}$ & $41 \cdot 0,102 \cdot 2$ \\
\hline Control & $73 \cdot 4$ & $55 \cdot 5,91 \cdot 6$ & $1 \cdot 3^{\mathrm{c}}$ & $-4 \cdot 3,6 \cdot 9$ & $4 \cdot 3^{\mathrm{C}}$ & $-0.3,8.9$ \\
\hline \multicolumn{7}{|c|}{ Plasma DHA $(\mu \mathrm{mol} / \mathrm{l})^{\star}$} \\
\hline EPA & $166 \cdot 5$ & $144 \cdot 3,189 \cdot 0$ & $48 \cdot 1^{d}$ & $11 \cdot 6,84 \cdot 6$ & $56 \cdot 6^{d}$ & $22 \cdot 2,91 \cdot 3$ \\
\hline $\mathrm{DHA}$ & $165 \cdot 6$ & $135 \cdot 8,195 \cdot 1$ & $216 \cdot 8^{e}$ & $110 \cdot 5,323 \cdot 0$ & $244 \cdot 5^{\mathrm{e}}$ & $146 \cdot 1,342 \cdot 8$ \\
\hline Control & $169 \cdot 9$ & $138 \cdot 2,201 \cdot 5$ & $12 \cdot 5^{f}$ & $-2 \cdot 7,27 \cdot 7$ & $17 \cdot 7^{f}$ & $5 \cdot 5,29.8$ \\
\hline \multicolumn{7}{|c|}{ Plasma oleic acid (mmol/l) } \\
\hline EPA & $1 \cdot 76$ & $1.58,1.93$ & 1.58 & $1.09,2.07$ & 1.68 & $1 \cdot 16,2 \cdot 20$ \\
\hline $\mathrm{DHA}$ & $1 \cdot 61$ & $1.47,1.74$ & 1.62 & $0.89,2.34$ & 1.68 & $0.94,2.41$ \\
\hline Control & 1.67 & $1.45,1.89$ & $2 \cdot 0$ & $1 \cdot 34,2 \cdot 66$ & $2 \cdot 22$ & $1.53,2.91$ \\
\hline \multicolumn{7}{|c|}{ Plasma TAG $(\mathrm{mmol} / \mathrm{l}) \S$} \\
\hline EPA & 0.89 & $0.77,1.03$ & 0.66 & $0.43,0.94$ & 0.75 & $0.51,1.03$ \\
\hline DHA & 0.79 & $0.69,0.90$ & 0.68 & $0.44,0.97$ & 0.73 & $0.49,1.01$ \\
\hline Control & 0.82 & $0.69,0.97$ & $0 \cdot 71$ & $0.52,0.91$ & 0.78 & $0.57,1.02$ \\
\hline \multicolumn{7}{|c|}{ Plasma NEFA (mmol/l) } \\
\hline EPA & 0.33 & $0.29,0.38$ & 0.23 & $0.15,0.32$ & 0.27 & $0.15,0.39$ \\
\hline DHA & 0.29 & $0.25,0.34$ & 0.25 & $0.17,0.33$ & 0.27 & $0.19,0.36$ \\
\hline Control & 0.33 & $0.29,0.38$ & 0.22 & $0.16,0.28$ & 0.27 & $0.18,0.35$ \\
\hline \multicolumn{7}{|c|}{ Plasma glucose (mmol/l) } \\
\hline EPA & $5 \cdot 11$ & $4 \cdot 96,5 \cdot 26$ & -0.09 & $-0.28,0.10$ & -0.07 & $-0.25,0.11$ \\
\hline $\mathrm{DHA}$ & $5 \cdot 12$ & $5 \cdot 02,5 \cdot 23$ & -0.10 & $-0.23,0.04$ & -0.10 & $-0.24,0.05$ \\
\hline Control & $5 \cdot 13$ & $4 \cdot 99,5 \cdot 27$ & -0.13 & $-0.29,0.03$ & -0.14 & $-0.31,0.02$ \\
\hline \multicolumn{7}{|c|}{ Plasma 8-iso-PGF $2 \alpha(p m o l / l) \neq \S$} \\
\hline EPA & $153 \cdot 1$ & $132 \cdot 9,176 \cdot 4$ & $22 \cdot 4$ & $10 \cdot 0,35 \cdot 7$ & $30 \cdot 4$ & $14 \cdot 0,48 \cdot 5$ \\
\hline $\mathrm{DHA}$ & $149 \cdot 4$ & $128 \cdot 6,173 \cdot 6$ & $8 \cdot 6$ & $-5 \cdot 5,24 \cdot 0$ & $16 \cdot 7$ & $4 \cdot 6,29 \cdot 8$ \\
\hline Control & $143 \cdot 8$ & $124 \cdot 6,166 \cdot 0$ & $8 \cdot 9$ & $-4 \cdot 1,23 \cdot 0$ & 14.5 & $4 \cdot 1,25 \cdot 6$ \\
\hline
\end{tabular}

a,b,c Mean values within a column with unlike superscript letters were significantly different $(P<0.001$; Bonferroni's multiple comparison test)

${ }^{\mathrm{d}, \mathrm{e}, \mathrm{f}}$ Mean values within a column with unlike superscript letters were significantly different $(P<0.01$; Bonferroni's multiple comparison test).

${ }^{*}$ Repeated-measures ANOVA of the changes at $5 \mathrm{~h}$ and immediately post-exercise from fasting $(0 \mathrm{~h}): P<0.001$, meal effect.

$\dagger$ Repeated-measures ANOVA of the changes at $5 \mathrm{~h}$ and immediately post-exercise from fasting $(0 \mathrm{~h}): P=0.01$, meal $\times$ time effect.

$\ddagger$ Repeated-measures ANOVA of the changes at $5 \mathrm{~h}$ and immediately post-exercise from fasting $(0 \mathrm{~h}): P=0.066$, meal effect.

$\S$ Geometric mean. 
to detect a 0.32 litres/min and $3.1 \mathrm{mmHg}$ change in cardiac output and diastolic BP, respectively. Data were logtransformed for plasma TAG and 8-iso- $\mathrm{PGF}_{2 \alpha}$ before analysis. Incremental area under the curve was calculated using the trapezoid rule. Data were analysed using repeated-measures ANOVA in SPSS (version 17.0; SPSS Inc., Chicago, IL, USA), with meal and time as within-subject factors. The Greenhouse-Geisser correction for sphericity was employed. Specific comparisons between the treatments were adjusted using the Bonferroni correction factor when there was a significant meal effect or meal $\times$ time interaction effect. Differences were considered significant at $P<0 \cdot 05$. Results are presented as means and $95 \% \mathrm{CI}$, unless otherwise specified.

\section{Results}

Of the thirty-eight subjects who were screened, twenty-four were enrolled in the study and data of twenty-two subjects were finally available for analysis, whose details are presented in Table 2. A CONSORT (Consolidated Standards of Reporting Trials) flow chart of the study participants (Fig. 2) is provided.

\section{Plasma fatty acid, TAG, NEFA, glucose and 8-isoprostane- $F_{2 \alpha}$ concentrations}

At $5 \mathrm{~h}$ following the EPA- and DHA-rich test meals, plasma EPA and DHA concentrations increased above fasting values by 321 and $131 \%$, respectively, and were significantly different from the control $(P<0 \cdot 001)$. There were no significant differences between the meals in plasma TAG, NEFA, glucose and 8 -iso-PGF $\mathrm{P}_{2 \alpha}$ concentrations $5 \mathrm{~h}$ following the test meals or immediately post-exercise (Table 3). However, average plasma TAG and NEFA concentrations were higher than fasting values $5 \mathrm{~h}$ following all test meals by 82 and $73 \%$, respectively $(P<0 \cdot 001)$. Plasma 8 -iso- $\mathrm{PGF}_{2 \alpha}$ concentrations
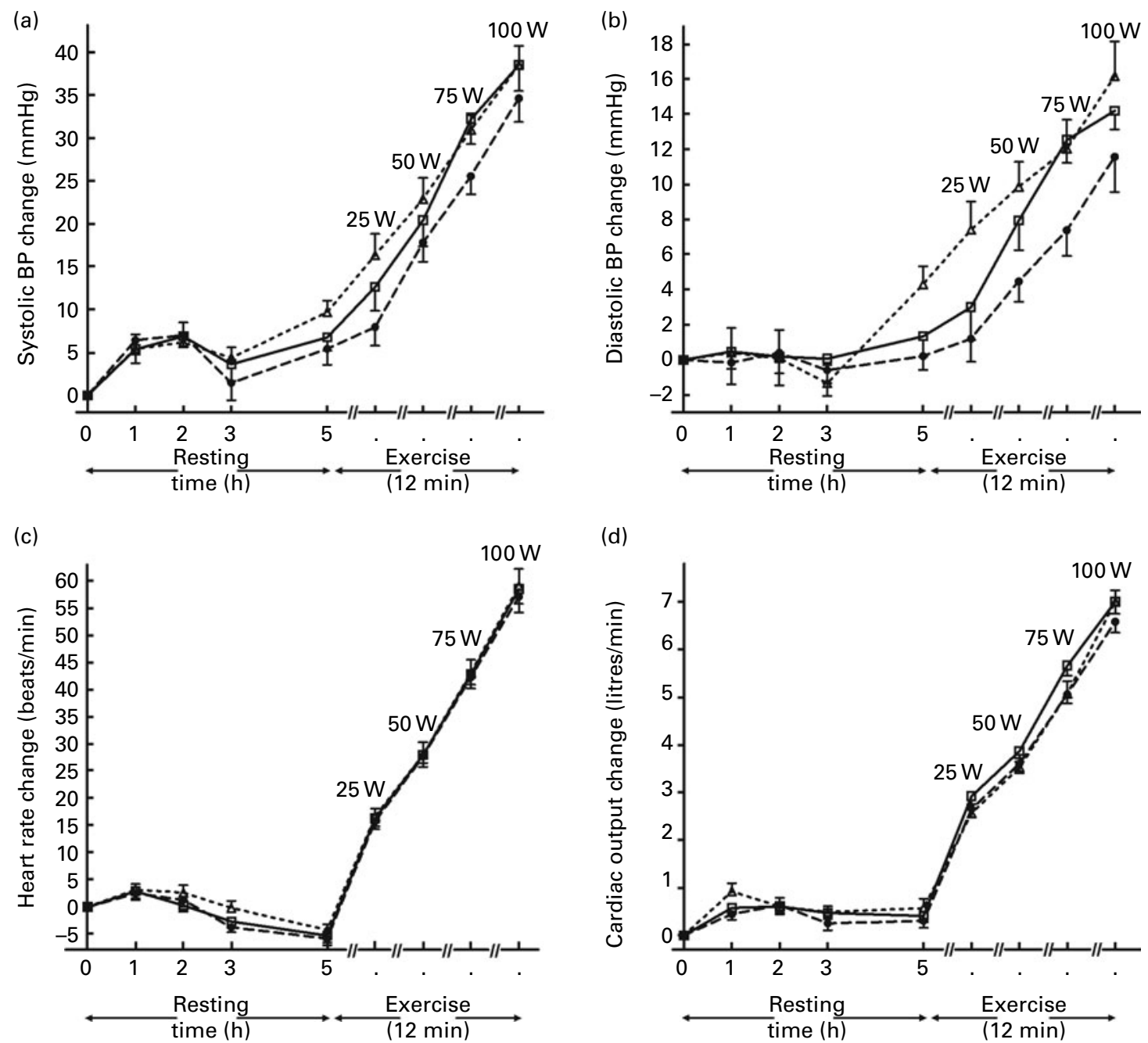

Fig. 3. Changes in (a) systolic blood pressure (BP; $n$ 19), (b) diastolic BP ( $n$ 19), (c) heart rate $(n$ 22) and (d) cardiac output $(n$ 22) after the EPA ( $\square$ ), DHA ( $)$ and control $(\Delta)$ meals from fasting $(0 \mathrm{~h})$ over a $5 \mathrm{~h}$ rest and during $12 \mathrm{~min}$ exercise in healthy men. Values are means, with their standard errors represented by vertical bars. Repeated-measures ANOVA of $5 \mathrm{~h}$ and $25,50,75,100 \mathrm{~W}$ exercise values: (a) meal effect, $P=0.020$; (b) meal effect, $P<0.001$, meal $\times$ time effect, $P=0.049$; (c) meal and meal $\times$ time effect, NS; (d) meal $\times$ time effect, $P=0.045$; (a-d) time effect, $P<0.001$. (a) DHA $v$. control, $P<0.025$; (b) DHA $v$. control, $P<0.001$; EPA $v$. DHA, $P<0.025$ (applied Bonferroni correction for three comparisons). Analysis of the changes from $5 \mathrm{~h}$ showed a significant meal $\times$ time effect $(P=0.007)$ only for diastolic BP. 
were higher than fasting values $5 \mathrm{~h}$ following the test meals and immediately post-exercise (overall effect, $P<0 \cdot 001$ ).

\section{Cardiovascular haemodynamics}

Fasting cardiac output, stroke volume and HR were on average $5.6(95 \%$ CI 5.3, 6.0) litres/min, 87.6 (95\% CI 80.1, 95.1) $\mathrm{ml}$ and 65.4 (95\% CI 62.3, 68.6) beats/min, respectively. Fasting systolic BP, diastolic BP, MAP and SVR were on average $116 \cdot 2$ (95\% CI 114.2, 118.2) $\mathrm{mmHg}, 71 \cdot 8$ (95\% CI 69.5, 74.2) $\mathrm{mmHg}, 88.5$ (95\% CI 86.4, 90.5) $\mathrm{mmHg}$ and $16 \cdot 1$ (95\% CI $15 \cdot 1,17 \cdot 2)$ Wood units, respectively. Fig. 3 shows the changes in (a, b) systolic and diastolic BP, (c) HR and (d) cardiac output following the meals at rest and during exercise. Resting measures of BP and cardiac output did not significantly differ between the meals. There was a sustained increase in systolic $\mathrm{BP}$ over $5 \mathrm{~h}$ following the meals. Exercise resulted in a marked increase in systolic and diastolic BP, and there were statistically significant meal $\times$ time interactions for the changes from $5 \mathrm{~h}$ in diastolic BP $(P=0.007)$ and MAP $(P=0.008)$ during exercise.

The test meals caused similar sustained increases in cardiac output over the $5 \mathrm{~h}$ resting postprandial period (at $5 \mathrm{~h}: 0 \cdot 4$ (95\% CI $0 \cdot 1,0 \cdot 8$ ) litres/min; $P=0.017)$ due to an effect mainly in stroke volume $(P<0 \cdot 001$; data not shown). Exercise resulted in distinct increases in $\mathrm{HR}$, with no differences between the meals, while for the increase in exercise cardiac output, there was a significant meal $\times$ time interaction effect $(P=0.045)$ for a comparison of the $5 \mathrm{~h}$ and $25,50,75$ and $100 \mathrm{~W}$ exercise values, but this became non-significant when the changes from the $5 \mathrm{~h}$ were compared. Fig. 4 shows mean SVR values $5 \mathrm{~h}$ postprandially and during exercise. Repeated-measures ANOVA of the 5h, 25, 50, 75 and $100 \mathrm{~W}$ values for SVR showed a significant meal effect $(P=0.003)$, with lower values after the DHA meal compared with the control meal by 0.57 (95\% CI 0.16, 0.99) Wood units $(P<0.01)$. Repeated-measures analysis of the changes in SVR from the $5 \mathrm{~h}$ resting value did not reveal any significant meal effect or meal $\times$ time interaction effect. At $15 \mathrm{~min}$ post-exercise, all haemodynamic variables were close to the pre-exercise and fasting values after all meals, with no significant differences observed between the meals. No other significant differences were observed.

\section{Discussion}

To our knowledge, this is the first study to investigate the acute effects of a single dose of EPA or DHA on haemodynamics at rest and in response to exercise. The decision to provide $4.7 \mathrm{~g}$ EPA or DHA was based on earlier reports showing their beneficial effects on vascular tone with such intakes $^{(11,12,15,16)}$, equivalent to $200-400 \mathrm{~g}$ oily fish, depending on the type of fish consumed ${ }^{(31)}$. In a previous report ${ }^{(24)}$, cardiac output was shown to increase following meals primarily due to an increase in stroke volume, as observed in the present study. It has also been demonstrated that exerciseinduced changes in cardiac output and HR measured $3 \mathrm{~h}$ following a high-fat meal of similar composition to the control meal used in the present study did not differ from those after

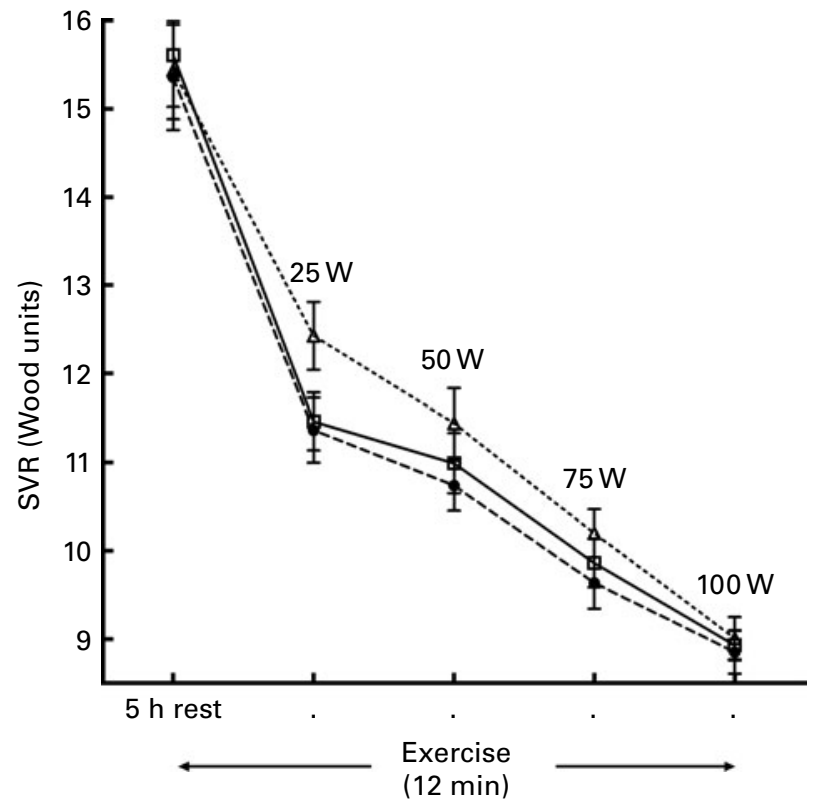

Fig. 4. Systemic vascular resistance (SVR) at $5 \mathrm{~h}$ of rest and during $12 \mathrm{~min}$ exercise after the EPA $(\square), \mathrm{DHA}(\bullet)$ and control $(\Delta)$ meals in healthy men ( $n$ 19). Values are means, with their standard errors represented by vertical bars. Repeated-measures ANOVA of $5 \mathrm{~h}$ and 25, 50,75, $100 \mathrm{~W}$ exercise values: meal effect, $P=0.003$; meal $\times$ time effect, NS; time effect, $P<0.001$. DHA v. control, $P<0.01$ (applied Bonferroni correction for three comparisons). Analysis of the changes from $5 \mathrm{~h}$ showed no significant meal effect or meal $\times$ time interaction effect.

a low-fat, high-carbohydrate meal ${ }^{(24)}$. In the present study, measurements were made in response to exercise $5 \mathrm{~h}$ after test meal consumption to correspond with the time of peak plasma concentrations of $n-3 \mathrm{LCP}^{(15)}$; plasma EPA and DHA concentrations were 321 and $131 \%$ greater than fasting values at $5 \mathrm{~h}$ following the EPA- and DHA-rich meals, respectively. There were no differences in cardiac output between the treatments. However, the DHA- but not EPA-rich meal $v$. control led to an attenuated increase in MAP at $5 \mathrm{~h}$ and during exercise. Calculation of SVR (MAP/cardiac output) suggests that the DHA-rich meal promoted vasodilation.

A number of mechanisms have been proposed for exercise vasodilation in response to $n$ - 3 LCP. Evidence from chronic studies suggests ${ }^{(32)}$ that it might be via the action of locally produced factors whereby EPA and DHA attenuate noradrenalineinduced forearm vasoconstriction ${ }^{(33,34)}$ and enhance dilatation and blood flow to contracting skeletal muscle ${ }^{(35)}$. These local factors may include increased NO bioavailability ${ }^{(6,7)}$, increased $\mathrm{PGI}_{2}$ and $\mathrm{PGI}_{3}$ production ${ }^{(8,9)}$, and changes in $\mathrm{EDHF}^{(10)}$. Since these endothelium-derived relaxing factors are also involved in exercise hyperaemia and the exercise-induced reduction in $\mathrm{SVR}^{(17-19)}$, their action might be enhanced by increases in their levels following the intake of $n$-3 LCP.

Plasma 8-iso- $\mathrm{PGF}_{2 \alpha}$ concentration was measured as an index of lipid peroxidation. The increase in 8 -iso-PGF $2 \alpha$ following the high-fat meals is in agreement with previous reports $^{(15,24,36)}$. This is in contrast to meals high in carbohydrate where plasma 8-iso- $\mathrm{PGF}_{2 \alpha}$ concentrations fall postprandially ${ }^{(24)}$. A limitation of the present study is that the assay used in the study was specific for measuring 
8-iso-PGF $2 \alpha$, the peroxidation product of arachidonic acid, and would not have detected any isoprostane metabolites derived from EPA or DHA which might exert physiological effects on the vascular system ${ }^{(37)}$.

Changes in exercise postprandial haemodynamic responses may be of greater physiological significance in relation to the risk of cardiovascular events than fasting resting measures. Supplementation with $n$-3 LCP for 5-12 weeks has been reported to reduce HR during exercise and improve HR variability during exercise in healthy athletes and overweight adults with CVD risk factors ${ }^{(38-40)}$ and enhance stroke volume and cardiac output responses to exercise in healthy adults ${ }^{(41)}$. However, a recent randomised controlled trial ${ }^{(42)}$ in 312 adults aged $45-70$ years found no effect on resting HR or $24 \mathrm{~h}$ ambulatory BP of supplementation with $n-3$ LCP up to $1.8 \mathrm{~g} / \mathrm{d}$, which was supplied mainly as EPA rather than DHA.

In conclusion, the present study shows no effect of an EPAor DHA-rich meal on cardiac output or stroke volume and provides tentative evidence for a vasodilator effect occurring $5 \mathrm{~h}$ following a high intake of DHA that appeared to be sustained during exercise.

\section{Acknowledgements}

This study was supported by the State Scholarships Foundation (I.K.Y.), Greece. The authors acknowledge financial support from the Department of Health via the National Institute for Health Research comprehensive Biomedical Research Centre award to Guy's and St Thomas' NHS Foundation Trust in partnership with King's College London. We thank Croda Chemicals Europe Limited, who donated the EPA-enriched oil (Incromega EPA 500TG SR) and DHA-enriched oil (Incromega DHA 500TG SR) used in the study. V. G. R. contributed to the design of the study, conducted the research (including cardiovascular measurements, phlebotomy, plasma 8-iso-PGF $2 \alpha$ and glucose analysis), statistically analysed and interpreted the data, and wrote the manuscript; W. L. H. contributed to the design of the study and test meal composition, and made critical revisions of the manuscript; S. P.-R., A. A. and R. C. participated in subject recruitment, assisted in data collection, and performed blood handling, TAG and NEFA analysis; S. P.-R. performed the plasma fatty acid analyses; T. A. B. S. conceived the hypothesis and contributed to the design of the study, contributed to data interpretation and made critical revisions to the manuscript. All authors read and approved the final version of the manuscript. The funders played no part in the study design, the collection or analysis of the data, the writing of the report or the decision to submit for publication. All authors are independent of the funders. The authors declare that they have no conflict of interest.

\section{References}

1. Geleijnse JM, Giltay EJ, Grobbee DE, et al. (2002) Blood pressure response to fish oil supplementation: metaregression analysis of randomized trials. J Hypertens 20 , 1493-1499.
2. Mori TA, Bao DQ, Burke V, et al. (1999) Docosahexaenoic acid but not eicosapentaenoic acid lowers ambulatory blood pressure and heart rate in humans. Hypertension $\mathbf{3 4}$, 253-260.

3. Mori TA \& Woodman RJ (2006) The independent effects of eicosapentaenoic acid and docosahexaenoic acid on cardiovascular risk factors in humans. Curr Opin Clin Nutr Metab Care 9, 95-104.

4. Demaison L, Blet J, Sergiel JP, et al. (2000) Effect of dietary polyunsaturated fatty acids on contractile function of hearts isolated from sedentary and trained rats. Reprod Nutr Dev 40, 113-125.

5. Mozaffarian D, Gottdiener JS \& Siscovick DS (2006) Intake of tuna or other broiled or baked fish versus fried fish and cardiac structure, function, and hemodynamics. Am J Cardiol 97, 216-222.

6. Li Q, Zhang Q, Wang M, et al. (2007) Docosahexaenoic acid affects endothelial nitric oxide synthase in caveolae. Arch Biochem Biophys 466, 250-259.

7. Li Q, Zhang Q, Wang M, et al. (2007) Eicosapentaenoic acid modifies lipid composition in caveolae and induces translocation of endothelial nitric oxide synthase. Biochimie 89, $169-177$.

8. Abeywardena MY, Fischer S, Schweer H, et al. (1989) In vivo formation of metabolites of prostaglandins I2 and I3 in the marmoset monkey (Callithrix jacchus) following dietary supplementation with tuna fish oil. Biochim Biophys Acta 1003, 161-166.

9. DeCaterina R, Giannessi D, Mazzone A, et al. (1990) Vascular prostacyclin is increased in patients ingesting omega-3 polyunsaturated fatty acids before coronary artery bypass graft surgery. Circulation 82, 428-438.

10. Matsumoto T, Nakayama N, Ishida K, et al. (2009) Eicosapentaenoic acid improves imbalance between vasodilator and vasoconstrictor actions of endothelium-derived factors in mesenteric arteries from rats at chronic stage of type 2 diabetes. J Pharmacol Exp Ther 329, 324-334.

11. West SG, Hecker KD, Mustad VA, et al. (2005) Acute effects of monounsaturated fatty acids with and without omega-3 fatty acids on vascular reactivity in individuals with type 2 diabetes. Diabetologia 48, 113-122.

12. Armah CK, Jackson KG, Doman I, et al. (2008) Fish oil fatty acids improve postprandial vascular reactivity in healthy men. Clin Sci (Lond) 114, 679-686.

13. Fahs CA, Yan H, Ranadive S, et al. (2010) The effect of acute fish-oil supplementation on endothelial function and arterial stiffness following a high-fat meal. Appl Physiol Nutr Metab 35, 294-302.

14. Newens KJ, Thompson AK, Jackson KG, et al. (2011) DHArich fish oil reverses the detrimental effects of saturated fatty acids on postprandial vascular reactivity. Am J Clin Nutr $\mathbf{9 4}$, 742-748.

15. Hall WL, Sanders KA, Sanders TA, et al. (2008) A high-fat meal enriched with eicosapentaenoic acid reduces postprandial arterial stiffness measured by digital volume pulse analysis in healthy men. J Nutr 138, 287-291.

16. Chong MF, Lockyer S, Saunders CJ, et al. (2010) Long chain $n-3$ PUFA-rich meal reduced postprandial measures of arterial stiffness. Clin Nutr 29, 678-681.

17. Hillig T, Krustrup P, Fleming I, et al. (2003) Cytochrome P450 2C9 plays an important role in the regulation of exerciseinduced skeletal muscle blood flow and oxygen uptake in humans. J Physiol 546, 307-314.

18. Dinenno FA \& Joyner MJ (2004) Combined NO and PG inhibition augments alpha-adrenergic vasoconstriction in 
contracting human skeletal muscle. Am J Physiol Heart Circ Physiol 287, H2576-H2584.

19. Boushel R, Langberg H, Gemmer C, et al. (2002) Combined inhibition of nitric oxide and prostaglandins reduces human skeletal muscle blood flow during exercise. J Physiol 543, 691-698.

20. Stewart KJ, Sung J, Silber HA, et al. (2004) Exaggerated exercise blood pressure is related to impaired endothelial vasodilator function. Am J Hypertens 17, 314-320.

21. Wilson MF, Sung BH, Pincomb GA, et al. (1990) Exaggerated pressure response to exercise in men at risk for systemic hypertension. Am J Cardiol 66, 731-736.

22. Singh JP, Larson MG, Manolio TA, et al. (1999) Blood pressure response during treadmill testing as a risk factor for new-onset hypertension. The Framingham Heart Study. Circulation 99, 1831-1836.

23. Brett SE, Ritter JM \& Chowienczyk PJ (2000) Diastolic blood pressure changes during exercise positively correlate with serum cholesterol and insulin resistance. Circulation 101, 611-615.

24. Rontoyanni VG, Chowienczyk PJ \& Sanders TA (2010) Postprandial lipaemia does not affect resting haemodynamic responses but does influence cardiovascular reactivity to dynamic exercise. Br J Nutr 104, 863-871.

25. Astrand PO \& Ryhming I (1954) A nomogram for calculation of aerobic capacity (physical fitness) from pulse rate during sub-maximal work. J Appl Physiol 7, 218-221.

26. Astrand I (1960) Aerobic work capacity in men and women with special reference to age. Acta Physiol Scand Suppl 49, $1-92$.

27. Brett SE, Jiang BY, Turner C, et al. (2006) Elevation of plasma homocysteine by methionine loading increases the diastolic blood pressure response to exercise. J Hypertens 24, 1985-1989.

28. Gizdulich P, Imholz BP, van den Meiracker AH, et al. (1996) Finapres tracking of systolic pressure and baroreflex sensitivity improved by waveform filtering. J Hypertens $\mathbf{1 4}$, 243-250.

29. Imholz BP, Wieling W, van Montfrans GA, et al. (1998) Fifteen years experience with finger arterial pressure monitoring: assessment of the technology. Cardiovasc Res $\mathbf{3 8}$, 605-616.

30. Rosell MS, Lloyd-Wright Z, Appleby PN, et al. (2005) Longchain $n$-3 polyunsaturated fatty acids in plasma in British meat-eating, vegetarian, and vegan men. Am J Clin Nutr 82, 327-334.

31. Simopoulos AP (1991) Omega-3 fatty acids in health and disease and in growth and development. Am J Clin Nutr $\mathbf{5 4}$, $438-463$

32. Monahan KD, Wilson TE \& Ray CA (2004) Omega-3 fatty acid supplementation augments sympathetic nerve activity responses to physiological stressors in humans. Hypertension 44, 732-738.

33. Chin JP, Gust AP, Nestel PJ, et al. (1993) Marine oils dosedependently inhibit vasoconstriction of forearm resistance vessels in humans. Hypertension 21, 22-28.

34. Mori TA, Watts GF, Burke V, et al. (2000) Differential effects of eicosapentaenoic acid and docosahexaenoic acid on vascular reactivity of the forearm microcirculation in hyperlipidemic, overweight men. Circulation 102, 1264-1269.

35. Walser B, Giordano RM \& Stebbins CL (2006) Supplementation with omega-3 polyunsaturated fatty acids augments brachial artery dilation and blood flow during forearm contraction. Eur J Appl Physiol 97, 347-354.

36. Berry SE, Tucker S, Banerji R, et al. (2008) Impaired postprandial endothelial function depends on the type of fat consumed by healthy men. J Nutr 138, 1910-1914.

37. Gao L, Yin H, Milne GL, et al. (2006) Formation of F-ring isoprostane-like compounds (F3-isoprostanes) in vivo from eicosapentaenoic acid. J Biol Chem 281, 14092-14099.

38. Buckley JD, Burgess S, Murphy KJ, et al. (2009) DHA-rich fish oil lowers heart rate during submaximal exercise in elite Australian Rules footballers. J Sci Med Sport 12, 503-507.

39. Ninio DM, Hill AM, Howe PR, et al. (2008) Docosahexaenoic acid-rich fish oil improves heart rate variability and heart rate responses to exercise in overweight adults. Br J Nutr 100, 1097-1103.

40. Peoples GE, McLennan PL, Howe PR, et al. (2008) Fish oil reduces heart rate and oxygen consumption during exercise. J Cardiovasc Pharmacol 52, 540-547.

41. Walser B \& Stebbins CL (2008) Omega-3 fatty acid supplementation enhances stroke volume and cardiac output during dynamic exercise. Eur J Appl Physiol 104, 455-461.

42. Sanders TA, Hall WL, Maniou Z, et al. (2011) Effect of low doses of long-chain $n$-3 PUFAs on endothelial function and arterial stiffness: a randomized controlled trial. Am J Clin Nutr 94, 973-980. 